\title{
ASPECTOS NEUROLÓGICOS DA DOENÇA DE CHAGAS: SISTEMA NERVOSO CENTRAL
}

\author{
Sylvio de Vergueiro ForJaz *
}

A leitura dos trabalhos de Carlos Chagas sôbre a tripanosomíase e a meditação sôbre afirmações quanto aos acometimentos do sistema nervoso central (SNC) nessa moléstia, suscita uma série de questões que os esforços de vários pesquisadores ainda não conseguiram dirimir.

Aos 30 anos de idade, Carlos Chagas, médico sanitarista, nunca havia sido neurologista militante, nem tampouco, neuropatologista. A pobreza dos recursos da Neurologia naquela época, sobretudo em pleno sertão, teria feito qualquer especialista de nossos dias desanimar antes do início de qualquer pesquisa, mesmo que a grandeza dos resultados lhe fôsse màgicamente revelada por antecipação. Daí o significado do trabalho dêste sábio brasileiro, cuja argúcia, associada a sólida cultura e fé inabalável nas próprias convicções, sustentaram a chama criadora, na qual moldou sua obra científica.

Entretanto, por muito que se admire o grande sábio e sua obra, no campo especial da Neurologia certas questões permanecem abertas: as manifestações sintomáticas que formam síndromes de Little e da diplegia cerebral espástica seriam realmente formas crônicas, evolutivas, da moléstia, como Chagas apontou, ou seriam simples seqüelas, "patias", ou mesmo manifestações de outras moléstias superpostas à tripanosomíase, com incidência acidentalmente acrescida nas populações flageladas em que Chagas descobriu seus primeiros doentes? Quais, então, as verdadeiras formas crônicas da moléstia conseqüentes às formas agudas tão bem configuradas? Como diagnosticá-las comprovadamente? Foi com o espírito voltado para tais incógnitas que reestudamos as publicações relacionadas com êste tema. Os comentários subseqüentes serão feitos com o objetivo de procurar respondê-las.

O acometimento do SNC na doença de Chagas resulta de dois meca-. nismos diversos: 1) a penetração do tripanosoma no eixo encefalomedular; 2) os acidentes embólicos na cardiopatia crônica. Constituem êstes últimos antes uma complicação neurológica que pròpriamente o substrato de uma forma clínica da doença. A designação de forma nervosa, de autoria do próprio Chagas $18,19,21$, tem sido habitualmente aplicada apenas às lesões e manifestações sintomáticas que resultam da invasão do SNC pelo T. cruzi.

Relatório apresentado ao I Congresso Brasileiro de Neurologia (Ribeirão Prêto, SP - 27 a 31 de junho de 1964).

* Docente de Neurocirurgia na Faculdade de Medicina de Ribeirão Prêto, da Universidade de São Paulo. 
Por outro lado, sob êste mesmo título deveriam ser estudados, também, os acometimentos do tripanosoma, que se manifestam por sintomas próprios de outros aparelhos (megaesôfago, megacolo, etc.), pois tais sintomas decorrem de alterações morfológicas viscerais ocasionadas por lesão das representações periféricas do sistema nervoso autônomo. A doença de Chagas é, essencialmente, uma "enfermidade do sistema nervoso" 42.

\section{FORMA NERVOSA DA DOENCA DE CHAGAS}

A Carlos Chagas 18, 19, 20 devemos as melhores descrições que a literatura médica consigna sôbre o acometimento do SNC na tripanosomiase. Os principais fatos clínicos, os conhecimentos básicos sôbre a patologia, os mais expressivos documentos iconográficos, acham-se ali resumidos de maneira simples, lúcida e convincente. Aos seus trabalhos, muitos outros se seguiram, particularmente, nos setores da Patologia clinica e experimental. No terreno da clínica, as contribuições foram menos numerosas e, em que pese a grande freqüência e importância que o descobridor da moléstia atribuiu à forma nervosa é, sem dúvida, êste o capítulo que menos interêsse tem merecido.

Como já postulava Carlos Chagas, é necessária a distinção entre formas nervosas agudas e crônicas, estas, de incidência maior, mas cuja legitimidade alguns autores põem em dúvida ${ }^{48}$. É que as transições entre estas formas no ser humano são, na verdade, desconhecidas, não havendo seqüência cronológica entre uma e outra.

Embora Chagas tivesse mencionado a possibilidade de evolução das formas agudas para as crônicas, nestas nunca se conseguiu individualizar clìnicamente a suposta fase meningencefálica aguda precedente 19, 22. As apontadas formas crônicas instalar-se-iam, assim, após uma fase aguda que, por motivos obscuros, seria assintomática.

Alguns autores, e entre êles o próprio Chagas ${ }^{22}$, calcados em verificaçōes experimentais e clínicas, aceitaram a possibilidade de infestação congênita da moléstia 11, 33, 36, 42, 56, 76. Segundo Chagas ${ }^{22}$, os portadores da forma nervosa crônica são justamente os que foram infestados durante o periodo fetal.

\section{A - InFEstą̧̃o aguda}

1) Sintomatologia - A infestação aguda caracterizada pela presença de tripanosomas no sangue periférico e mesmo no líquido cefalorraqueano, acomete de preferência a lactantes $19,30,34,49,50,64,67$ e tem alto indice de letalidade.

Além das manifestações sintomáticas próprias das lesões do SNC, apresentam os doentes também outros sinais gerais, como febre alta e continua, fácies edemaciado, adenopatias generalizadas, hépato e esplenomegalia de grandes proporções, transudaçōes nas cavidades serosas, anorexia, vômitos, diarrëia e bronquite $3,4,7,23,24,26,34$. Os sintomas neurológicos são os peculiares às meningoencefalomielites difusas e ocioso seria enumerá-los 18, 19, 
$21,30,49,50,53,64,67,71$. Referências às lesões de inoculação constam, em geral, das informaçōes anamnésticas ou sã̃o verificadas ao exame: edema palpebral elástico e indolor, conjuntivite e dacrioadenite unilaterais, enfartamento ganglionar pré-auricular, parotídeo ou submaxilar (complexo oftalmoganglionar, sinal de Romaña) ou tumefação cutânea, inflamatória, na face, pescoço ou membros superiores, com enfartamento ganglionar satélite (chagomas).

A comprovação diagnóstica é feita pela demonstração da existência de parasitos no sangue periférico, pelo xenodiagnóstico ou pela cultura e inoculação do sangue em animais sensiveis ${ }^{31,32,82}$. A reação de fixação de complemento (Machado-Guerreiro) praticada no sangue, pelo baixo índice de positividade comprovado nesses casos agudos, constitui recurso de muito menor valor do que nas formas crônicas ${ }^{32,82}$.

As escassas publicações que tratam de resultados dos exames praticados no líquido cefalorraqueano (LCR) não permitem uma tomada de posição segura sôbre o real significado dêsse recurso para subsidiar o diagnóstico. Chagas 18,19 inoculando animais sensiveis com amostras de LCR de seus pacientes, logrou isolar o parasito numerosas vêzes. Pedreira de Freitas ${ }^{34}$ referiu o mesmo fato, num paciente portador da forma aguda, mas sem manifestações sintomáticas próprias do SNC e no qual o exame bioquímico do LCR resultou normal. Dias ${ }^{2} \bar{i}$ observou a positividade da reação de Machado-Guerreiro no LCR de um paciente com forma cardiaca crônica, mas também de neurocisticercose. Em 11 enfermos com formas agudas não neurológicas observadas por Amato Neto ", o LCR apresentou-se rigorosamente negativo. Observação idêntica foi publicada por Dias e col. ${ }^{26}$ a propósito de um caso. Dalma ${ }^{25}$, porém, obteve positividade da reação de fixação de complemento com antígeno tripanosômico em 4 pacientes com formas agudas não nervosas. Dos que praticaram êstes exames em pacientes com formas agudas nervosas, Martinez Colombres e col. ${ }^{49}$ encontraram a pressão inicial elevada e as reaçōes das globulinas positivas em 8 casos.

Recente publicação de Elejalde ${ }^{28}$ refere resultados dos exames de LCR em amostras extraídas por punção lombar de 4 pacientes com acometimento chagásico agudo do SNC, nos quais foi reconhecida a presença do tripanosoma no sangue periférico; o autor observou hiperproteinorraquia, hipercitose moderada (até 60 células), positividade das reações das globulinas ( 2 vêzes) e positividade da reação de Machado-Guerreiro (2 vêzes). Em uma amostra, a reação da precipitina revelou-se também positiva. O diagrama eletroforético foi estudado em uma das amostras e revelou grande aumento da fração albumina. Elejalde apresenta ainda, para confronto, os resultados de exames de LCR de 7 pacientes também chagásicos, mas com formas crônicas, nos quais todos os dados foram rigorosamente negativos.

Outras provas laboratoriais não são especialmente instrutivas nestas formas da moléstia. Não há referência, nos trabalhos publicados, a resultados de exames eletrencefalográficos em pacientes portadores das formas nervosas agudas.

2) Patologia - Vencida a barreira linfática inicial representada pelo complexo oftalmoganglionar ou chagoma de inoculação, os parasitos inva- 
dem a circulação sangüínea, migrando para vários tecidos, acometendo, particularmente, as fibras musculares e a neuroglia. Foi Gaspar Vianna 72 o primeiro a demonstrar o parasitismo das células gliais, achado corroborado por outros pesquisadores, esclarecendo-se que não só a astroglia é parasitada, mas, também e particularmente, a microglia $70,79,80,81$.

Invadido o elemento hospedeiro, o tripanosoma assume a forma de leishmânia e inicia suas multiplicações binárias sucessivas até ocupar tôda a célula, cujo núcleo é rejeitado para a periferia. Kofoid e col. ${ }^{44}$ e Romaña e Meyer ${ }^{66}$ estudaram o fenômeno "in vitro". De acôrdo com os últimos, êste ciclo dura 5 dias. Em sua última etapa, surgem entre as leishmânias formas menores e depois flageladas que, ativamente, abandonam a célula hospedeira, a qual termina por romper-se, libertando todos os parasitos no meio exterior. As formas em leishmânias não têm resistência nem capacidade de maturação fora das células hospedeiras e, assim, livres no tecido, degeneram e desintegram-se, provocando reações inflamatórias localizadas e, fato dos mais importantes, lesões liticas eletivas das células nervosas circunjacentes. Esste último episódio, reconhecido já por Gaspar Vianna ${ }^{72}$, foi corroborado mais tarde por outros $16,40,41,42,55,79$, mas ainda é negado por alguns $2,28,70$.

Köberle 40,43 , aceitando uma hipótese de Torres e Villaça ${ }^{70}$, que admitiram a existência de uma "noxina tripanosômica", acredita que a desintegração das leishmânias liberta uma substância nociva para os neurônios, uma endotoxina cuja natureza bioquímica ainda não pôde ser determinada. Em culturas de tecidos, Musacchio e Meyer ${ }^{54}$ não lograram observar qualquer ação tóxica do $T$. cruzi degenerado ou morto sôbre células nervosas, porém, tratava-se de culturas de embrião de galinha e é sabido que as aves em geral são resistentes à agressão tripanosômica.

As destruições neuronais do sistema nervoso processam-se, pois, na fase aguda "quando se decide a sorte o chagásico" 40,41, 42, 43. As afirmações de Chagas e Vianna na primeira década do século foram, em sua maior parte, confirmadas por verificações subseqüentes. No setor clínico-neurológico, Austregésilo ${ }^{6}$, Borges Fortes ${ }^{8}$, Colares Moreira ${ }^{53}$ e Villela ${ }^{75}$, entre outros $30,34,39,45,46,50,5 \hbar^{2}, 62,64,65,67,75$, publicaram valiosas observações sôbre o assunto. Tiveram oportunidade, os três primeiros, de examinar "in loco", nas próprias zonas flageladas os doentes apontados por Chagas como vítimas das formas nervosas, reconhecendo sua autenticidade neurológica, descrevendo seus sintomas, agrupando e classificando as formas clínicas observadas. No setor da Patologia clínica, também as constataçōes foram confirmadas várias vêzes $2,29,40,41,42,43,55$ em perfeita identidade com os achados em animais de experimentação.

Mais numerosas, porém, que as de outros setores, foram as contribuições da Patologia experimental, entre as quais sobressaem as de Torres e col., de Villela e col., de Souza Campos e, mais recentemente, de Köberle, de Vichi, de Brandão, de Alencar e de Elejalde. Torres, Villela e Souza Campos, em pesquisas individuais $11,12,13,14,15,16,70, \pi 7,78$, inocularam cães com cepas neurotrópicas e virulentas de $T$. cruzi isoladas de tatus, verificando o aparecimento de sinais neurológicos (paraplegia, convulsões, ataxia), 
estudando anátomo-patològicamente o SNC após o óbito espontâneo ou provocado, confirmando a existência das lesões histopatológicas fundamentais: granulomas esparsos, tanto na substância branca quanto na cinzenta do encéfalo e medula ${ }^{70},{ }^{79}$, presença das leishmânias no interior das células da neuroglia (astroglia e microglia) ${ }^{80,81}$ e, mais raramente, nas células neuronais ${ }^{81}$, fenômenos degenerativos dos neurônios adjacentes aos granulomas 16, 79 , das células de Purkinje, das células piramidais e, menos acentuadamente, das células ganglionares da medula ${ }^{12,80}$, infiltrados inflamatórios meníngeos e lesões vasculares adventiciais e da intima $14,79,77,79,80$.

Köberle e col. estudaram principalmente as lesões degenerativas das representaçōes periféricas do sistema nervoso autônomo visceral, intramural $9,40,41,42,43$ com método inteiramente diverso dos autores que os precederam; fazendo contagens neuronais em sêres humanos portadores de aperistalse e enteromegalias ${ }^{43}$ e em animais inoculados artificialmente, verificaram diminuição do número das células nervosas dos plexos intramurais.

Tais pesquisas feitas também no SNC - no cerebelo, por Jardim ${ }^{37}$; na medula espinhal, por Schwartzburd e Köberle 69 — permitiram verificar diminuiçōes significantes no número de células de Purkinje e das células ganglionares da medula. A maior ou menor densidade de infestação parasitária foi também pesquisada na medula de ratos $i 3, \tau 4$, tendo ficado patente que a substância cinzenta da região lombar é a mais atingida, fato relacionado, provàvelmente, com o predomínio das manifestações clínicas da paraplegia, observadas em animais de experiência e com a forma pseudotabética a que faz referência Austregésilo ".

Em resumo, nenhuma dúvida pode subsistir quanto à existência das formas nervosas agudas da doença de Chagas, diante da esmagadora evidência clínica e laboratorial acumulada. A reprodução experimental das meningo-encefalomielites difusas em cães e ratos com evidentes manifestações neurológicas (paraplegia, ataxia, convulsões), constitui outra etapa importante para a legitimação das observações clínicas e necrópsicas.

B — INFEstaÇÃO CRÔNICA

1) Sintomatologia - A ocorrência de numerosos casos de encefalopatias infantis nas zonas flageladas pela tripanosomíase, não passou despercebida a Carlos Chagas que, intuitivamente, os filiou à mesma etiologia comprovada para as meningo-encefalomielites difusas agudas. Ainda que muito mais freqüentes do que as formas nervosas agudas, estas formas nervosas crônicas, não representavam mais do que $10 \%$ das formas crônicas em geral da moléstia ${ }^{19}$. As sindromes mais freqüentemente observadas eram as da diplegia cerebral espástica e de Little, atingindo lactentes e adolescentes ou adultos que vinham arrastando sua enfermidade desde os primeiros dias de vida. Paralisia e espasmodicidade combinadas em graus os mais variados, atingindo sobretudo os membros inferiores, acompanhadas, ou não, de movimentos involuntários atetosiformes, assumindo outras vêzes o tipo pseudo-bulbar, sempre com graves deficiências mentais, indo até a idiotia, surdomudez por vêzes, tal era o quadro sintomatológico com que se defrontavam 
freqüentemente os primeiros neurologistas que Carlos Chagas e Oswaldo Cruz conduziram às zonas flageladas. Outros traços sintomatológicos importantes que definiam tais enfermos eram as síndromes convulsivas, os distúrbios da linguagem e a ataxia cerebelar.

Austregésilo ${ }^{6}$ classificou as formas neurológicas em cinco grupos (diplégicas, convulsivas, cerebelares, extrapiramidais e psiquicas). No primeiro grupo incluiu as sindromes de Little, da dupla hemiplegia e a pseudobulbar, que assinalou como das mais freqüentes, pois manifestações como disartria, disfagia, riso e chôro espasmódico, fácies amímico, paresia facial bilateral com incontinência da saliva, foram os sintomas mais encontrados pelos que puderam examinar tais enfermos. Refere ainda êste autor pesquisas de Galloti e Azevedo que teriam conseguido provocar, em cães, pela inoculação intratecal de $T$. cruzi, uma síndrome pseudotabética. Não conseguimos localizar na literatura a publicação correspondente.

Disse Chagas ${ }^{19}$ que, relativamente à freqüência dessas formas nervosas crônicas, reuniu numerosas observações "que o autorizavam a afirmar que essa doença é a que, talvez, provoque, em patologia humana, o maior número de afecçōes orgânicas do sistema nervoso central". Em 1913, afiançava Chagas já possuir "para mais de 200 observações de casos dêsse tipo".

Um outro fato, entretanto, também não lhe passou despercebido: é que na pesquisa dos antecedentes de tais casos crônicos era impossível individualizar a pressuposta fase pregressa da infecção aguda ${ }^{19,22}$. A evolução ràpidamente mortal dos casos de infestação meningo-encefalomielítica também não permitia acompanhá-los até a fase crônica, frustrando, assim, o reconhecimento das formas de transição. Não obstante Chagas admitiu ter acumulado provas irrefutáveis da etiologia chagásica destas formas, inclusive, segundo afirmou, com evidências anátomo-patológicas da presença dos tripanosomas nas lesões cerebrais. Borges-Fortes ${ }^{8}$, em publicação pertinente, refere um caso com manifestações neurológicas crônicas, estacionárias e que, ao exame necroscópico, apresentava parasitos sob forma de leishmânias infestando células da microglia cerebral.

Outros autores, entretanto, não reconheceram em populações flageladas que examinaram, a presença dessas síndromes referidas por Chagas ${ }^{45}$, quase todos salientando as dificuldades em conceituar tais formas $32,33,34,35,50$, enquanto outros, simplesmente, negam sua existência ${ }^{2,48}$. O próprio Chagas, num de seus últimos trabalhos ${ }^{22}$, assinalava que a demonstração da transmissibilidade congênita da doença feita por Nathan Larrier 56,57 e Villela ${ }^{76}$, “permitiu o esclarecimento dessa incógnita patogênica", representada pela relativa abundância das chamadas formas nervosas crônicas sem antecedentes da fase aguda, em contraste com a altíssima mortalidade dos casos de meningo-encefalomielite aguda. Com efeito: a possibilidade de uma fase aguda durante a vida embrionária ajustava-se melhor às constatações clínicas das formas crônicas mencionadas: encefalopatias infantis com manifestações sintomáticas presentes desde os primeiros dias e atingindo um número desproporcionado de pacientes, dada a altíssima letalidade verificada para as formas meningo-encefalomieliticas agudas. 
Referiu Chagas ${ }^{19}$ que outras etiologias foram cuidadosamente excluídas em cada caso, pelo estudo dos antecedentes e exames laboratoriais. Ninguém ignora as grandes dificuldades com que se defrontam os neurologistas para o esclarecimento do diagnóstico etiológico em casos com manifestações enquadráveis nas síndromes diplégicas cérebro-cerebelares congênitas e de Little. Traumatismos obstétricos, prematuridade, asfixia do recémnascido, defeitos do desenvolvimento embrionário e infecção ou infestação fetal foram, sucessivamente, imputados no correr dos tempos, como os fatôres mais importantes, porém todos os tratadistas comentam os enormes precalços, por vêzes a impossibilidade mesmo, de levar a têrmo tais esclarecimentos na grande maioria dos casos. No conjunto polimorfo dos elementos invocados, a infestação congênita pelo tripanosoma, tal como a de outros parasitos, poderia obviamente ter o seu lugar, mas a aceitação dessa hipótese teria que se sujeitar a demonstraçōes objetivas mais evidentes e numerosas.

A sistematização das várias formas crônicas da moléstia, tal como o próprio Chagas propôs, inspirou-se naturalmente na predominância clínica e não na exclusividade dos sintomas.

A coexistência de manifestações de vários órgãos ou sistemas é comum e, portanto, facilita o reconhecimento etiológico: os sintomas cardiacos, por exemplo, apresentam-se com freqüência nas formas nervosas crônicas, sempre com alterações eletrocardiográficas dos mais variados tipos. Mas, além disso, há ainda os sintomas gerais, como a hiperplasia ganglionar generalizada, a hepatosplenomegalia, a infiltração edematosa e crepitante da pele que se apresenta com coloração bronzeado-violácea típica e os surtos febris recidivantes. São êstes, outros elementos sintomáticos da moléstia, que sugerem o diagnóstico, diante dos casos concretos de diplegia espasmódica ou sindrome de Little.

O estudo da função tireoidiana na forma crônica da doença levou Lomonaco ${ }^{47}$ a suspeitar de que as variações freqüentes dos valôres da taxa de iôdo ligado à proteína, decorressem de lesões hipotalâmicas. As anormalidades das curvas glicêmicas observadas por Reis ${ }^{60}$ nessas mesmas condições, poderiam, embora muito mais problemàticamente, depender também de lesões do SNC.

Uma das grandes dificuldades no diagnóstico de tais casos reside no fato de serem quase sempre negativos os resultados do exame do LCR. Chagas referiu que a sua inoculação em animais sensiveis era de resultados positivos. Cita objetivamente um caso de diplegia espástica e dois de ataxia cerebelar, dos quais amostras de LCR inoculadas em cobaios revelaram a presença do $T$. cruzi ${ }^{19}$. A reação de Machado-Guerreiro, de alto índice de positividade, quando realizada no sangue de pacientes com formas crônicas $\left(97,3 \%\right.$, segundo Freitas $\left.{ }^{31}\right)$, quase sempre é negativa quando praticada no LCR. Segundo Mello ${ }^{52}$ esta negatividade é tanto mais provável quanto mais antiga seja a doença. É o que referem Käfer e col. ${ }^{39}$ em 11 casos, Elejalde $^{28}$ em 7, Basso ${ }^{7}$ em 10 e Pedreira de Freitas ${ }^{35}$ em 46, casos êstes todos nos quais o diagnóstico foi firmado pela positividade da reação de fixação de complemento no sangue, além de achados clínicos. Jardim ${ }^{38}$ informou-nos ter acumulado 30 casos de pacientes internados em frenocômio, 
com doenças mentais variadas, todos com reação de Machado-Guerreiro positiva no sangue, nos quais essa mesma reação, praticada no LCR revelou-se negativa. Nos casos dêstes vários autores, aliás, outros exames bioquímicos praticados no LCR mostraram-se também negativos. Entretanto, Villela e Bicalho ${ }^{82}$ assinalaram positividade da reação de Machado-Guerreiro no LCR em 3 de 4 enfermos com formas nervosas crônicas da moléstia. Villela ${ }^{i 5}$, em publicação contemporânea à anterior, assinala que esta reação "é por vêzes positiva nas formas nervosas crônicas", sem referir qualquer caso concreto.

Käfer e col. ${ }^{39}$ referem resultados de exame eletrencefalográfico em 30 pacientes nos quais a reação de Machado-Guerreiro foi positiva no sangue: os traçados apresentaram-se anormais em 50\% dos pacientes. Sem diminuir a importância desta verificação, é forçoso admitir que as alteraçōes eletrencefalográficas não servem de apoio para suspeitas etiológicas nestes casos.

Do ponto de vista anátomo-patológico, afora afirmações do próprio Chagas ${ }^{19}$ e o caso referido por Borges-Fortes ${ }^{8}$, nenhum outro autor publicou achados parasitológicos convincentes em casos clínicos análogos de diplegia cerebral espástica ou quaisquer outras síndromes neurológicas. Até mesmo em animais de experimentação, demonstrações histológicas da presença do parasito são raras durante a fase crônica.

Torna-se, assim, extremamente difícil sair do campo fértil das simples suspeitas diagnósticas e penetrar no terreno sólido das demonstrações convincentes. Como já observou alguém, "o que é difícil é o arremate diagnóstico dêsses casos". Considere-se, entretanto, que a patogenia e as alterações histopatológicas de várias moléstias do SNC não foram ainda suficientemente demonstradas, o que não lhes rouba suas prerrogativas nosológicas, nem a crença nas teorias que serviram de base para sua caracterização clínica.

Aliás, diante das fartas demonstrações experimentais acumuladas por Köberle e vários de seus colaboradores a respeito das reduções da população neuronal no cerebelo e medula de animais inoculados com $T$. cruzi, é de se supor que, dentro de pouco tempo possam ser objetivadas as reais lesões neurológicas dos casos humanos de formas nervosas crônicas desta doença.

Brandão ${ }^{10}$ nos informou sôbre recente verificação dêsse tipo em paciente chagásico crônico com sintomas medulares e cerebelares e reação de Machado-Guerreiro positiva no sangue; as contagens neuronais no cerebelo revelaram-se flagrantemente diminuidas, frente aos casos normais.

Melaragno ${ }^{51}$ ao abordar o problema da etiologia das tromboses carotideas, menciona a doença de Chagas como fator de lesão do endotélio vascular, citando Zaclis e col. ${ }^{84}$ que registraram dois casos de trombose da carótida interna em pacientes com doença de Chagas, sem, no entanto, imputar a esta etiologia o processo que observaram. Lesões vasculares endoteliais e adventiciais foram assinaladas por Villela ${ }^{i}$, Villela e Torres ${ }^{i 9,80}$ e Souza Campos ${ }^{13}$. Recentemente, Okumura e col.59 publicaram resultados de pes- 
quisas experimentais a respeito, esclarecendo problemas da patogenia de tais lesões.

Embora não conste na literatura por nós consultada qualquer referência objetiva sôbre achados clínicos ou anátomo-patológicos de lesões do SNC decorrentes de tromboses de grandes vasos com esta etiologia, é fácil supor, por analogia com o que se observa em processos semelhantes de outras etiologias parasitárias, que tais fenômenos devem existir. É mesmo possível que alguns casos catalogados como de embolia cerebral sejam, na realidade, de trombose. Nussenzveig e col. ${ }^{58}$ citam, entre os 8 casos de embolia que apresentaram, um que, ao exame necroscópico, apresentava a artéria cerebral média ocluida por processo trombótico.

Em resumo: 1) numerosos pesquisadores não têm conseguido demonstrar a presença do T. cruzi no SNC de pacientes com as chamadas "formas nervosas crônicas" da doença de Chagas (diplegias cérebro-cerebelares congênitas, síndromes de Little), tal como no passado outros o fizeram; 2) as diplegias cérebro-cerebelares congênitas e a sindrome de Little seriam antes seqüelas de processos lesionais do SNC e não expressões de uma "forma crônica" evolutiva da doença de Chagas; 3) as verificações experimentais e necroscópicas estão a apontar as lesões degenerativas neuronais expressadas pelas diminuiçōes numéricas, como representativas do verdadeiro quadro anátomo-patológico da fase crônica do acometimento do SNC pelo $T$. cruzi; 4) a única comprovação diagnóstica laboratorial útil de que dispomos em tais casos é representada pela positividade da reação de Machado-Guerreiro no sangue.

\section{EMBOLIAS CEREBRAIS NA CARDIOPATIA CHAGÁSICA}

$\mathrm{Na}$ região apical do ventrículo esquerdo dos corações chagásicos forma-se freqüentemente uma lesão hipoxêmica ("lesão da ponta"), já demonstrada à saciedade tanto em material de necropsias 5,41,43 quanto eletrocardiogràficamente ${ }^{45}$. São microenfartes e às vêzes necroses isquêmicas, macroscòpicamente visíveis, que resultam de uma insuficiência coronária relativa, dada a exigência muito aumentada de oxigênio pela fibra cardíaca. Em muitos casos uma autêntica dilatação aneurismática chega a se formar nesse local, favorecendo a estase sangüínea. Freqüentes vêzes o processo inflamatório miocárdico propaga-se até o endocárdio parietal ${ }^{5}$. Em virtude dêsses dois fenômenos - estase sangüínea e lesão endotelial - formam-se trombos murais, cujo desgarramento provoca embolias e enfartes em vários órgãos, tanto da pequena quanto da grande circulação.

Em 77 de 93 pacientes com forma cardíaca crônica da doença de Chagas necropsiados por Andrade ${ }^{5}$, foram encontrados fenômenos embólicos em vários órgãos: em $75 \%$ dêstes pacientes havia trombos murais intracardiacos; em 10, as embolias produziram enfartes cerebrais, com manifestações sintomáticas evidentes. Excetuando-se dois pacientes que tiveram sobrevida de 4 e 2 meses, respectivamente, todos os outros faleceram após um prazo médio de 7 dias, fato que atesta a gravidade destas lesões. 
Tais fenômenos foram pela primeira vez referidos por Nussenzveig e col. em $1953^{58}$. Estes autores apresentaram as observações de 8 pacientes com diagnóstico comprovado de forma cardíaca crônica da doença de Chagas, com reação de Machado-Guerreiro positiva no sangue, todos com acidentes vasculares cerebrais, de que resultaram hemiplegias, recidivantes em dois pacientes, tendo quatro falecido com poucos dias de evolução da moléstia; o exame necroscópico confirmou a natureza das lesões cerebrais: amolecimentos isquêmicos em 7 e amolecimento hemorrágico em um caso; a presença de trombos murais cardíacos foi verificada em 3 dos 4 casos autopsiados. Riu e Genis ${ }^{63}$ apresentaram também um caso dessa mesma natureza; sua documentação, entretanto, foi menos sugestiva.

Ressalta das referências acima reproduzidas o caráter convincente dos. achados anátomo-patológicos, particularmente, na publicação de Andrade. Os aspectos sintomáticos neurológicos nada têm de particular. A gravidade das lesões é atestada pela alta mortalidade e pela reduzida sobrevida. A eventualidade de recidivas é patente das informações clínicas e das verificaçōes necroscópicas.

\section{SUMMARY}

\section{Neurological aspects of Chagas' disease: central nervous system}

The lesions of the nervous system in the Trypanosomiasis Cruzi are quite frequent and are not only limited to the encephalo-spinal-axis. Actually, they are much more common in the peripheral representations of the autonomic nervous system, resulting in the so-called enteromegalies (megaesophagus, megacolon, etc.) so frequent in Brazil. However, only the clinical manifestations due to the encephalic and spinal lesions have been included in the neurological aspects of Chagas' disease (as formerly contended for by Carlos Chagas).

In the acute phase of the central nervous system infestation, the Trypanosoma cruzi, as leishmanias, is found in cellular elements of the neuroglia (microglia, astroglia) and may be isolated from the peripheral blood and cerebrospinal fluid (inoculation in sensitive animals). The corresponding clinical manifestations are the severe difuse meningo-encephalo-myelitis with a high degree of lethality and also signs of infection, hepatomegaly and splenomegaly. The infants from endemic areas are much more compromised. The clinical-pathologic as well as experimental confirmations on that acute phase of the disease are numerous and irrefutable.

In the chronic phase of the disease, the neurological manifestations are not very clear. Early in 1909, Chagas, impressed with the great number of cases of infantile encephalopathy found in infested regions, imputed to the $T$. cruzi the etiology of such cases of encephalopathy and considered them as pertaining to a chronic phase of the disease. This has not been confirmed by other investigations, and even if the etiologic agent were 
the $T$. cruzi the clinical manifestations have no evolutive character and seem more sequelae than symptoms of a real chronic nervous phase. Even experimentally it has not been possible to demonstrate the presence of parasites in the nervous system of infested animals after clearing of the signs of the acute phase.

In patients with chronic Chagas' disease with lesions in several organs and with nervous symptoms (especially mental disturbances) it has not been possible to get positive results from the complement fixation test (MachadoGuerreiro's reaction) when performed using cerebrospinal fluid, yet this test is positive in about $97 \%$ of the cases when blood is used instead.

Recently, Köberle and coworkers have shown a great diminution in the number of nerve cells in the intramural plexuses of hollow viscera and in the cerebellum and spinal cord of men and experimental animals with Chagas' disease. It is hoped this approach using neuronal courtings will in a near future show which are the true cases of chronic Chagas nervous disease.

Regarding the embolic phenomena of Chagas heart disease, they do not have particular symptomatological aspects, except the high degree of mortality. Theoretically, cerebral thrombotic phenomena may also develop under the same etiology, but they have not been demonstrated through a pathological study.

\section{REFERENCIAS}

1. ALENCAR, A. - Histogênese do granuloma chagásico do sistema nervoso central do cão. Anais II Congr. Lat. Amer. Anat. Patol. 51-52, 1958.

2. ALENCAR, A. \& ELEJALDE, P. - O sistema nervoso central na infestação experimental do camundongo albino pelo Schisotripanum cruzi. An. Congr. Intern. Doença de Chagas 1:25-34, 1959.

3. AMATo NETO, V. - Contribuição ao conhecimento da forma aguda da doença de Chagas. Tese de Livre-Docência, Faculdade de Medicina da Universidade de São Paulo, 1958.

4. AmAto NETO, V. \& MEIRA, J. A. - Forma aguda da doenca de Chagas. An. Congr. Intern. Doença de Chagas 1:64-72, Rio de Janeiro, 1959.

5. ANDRADE, Z. A. - Fenômenos trombo-embólicos na cardiopatia chagásica. An. Congr. Intern. Doença de Chagas 1:73-84, Rio de Janeiro, 1959.

6. AUSTREgésilo, A. - Formes nerveuses de la maladie de Chagas. Rev. Neurol. 1:1-21, 1927.

7. BASSO, G. \& BASSO, R. - Estudios de enfermos del Asilo de Mendigos de Mendoza con reacción de Machado positiva. III Reunión Soc. Argent. Pat. Reg., Buenos Aires, 1936.

8. BORGES FORTES, A. - As lesões do sistema nervoso na enfermidade de Chagas. J. Clin. (Rio de Janeiro) 23:353-361, 1942. 
9. BRANDÃO, H. J. S. - Moléstia de Chagas experimental: estudo quantitativo de neurônios simpáticos e parassimpáticos. Hospital (Rio de Janeiro) 61:137$154,1962$.

10. BRANDAO, H. J. S. - Comunicação pessoal.

11. CAMPoS, E. de S. - Sur la paraplégie des animaux infectés expérimentalement avec le Trypanosoma cruzi. C. R. Soc. Biol. (Paris) 91:984-985, 1924.

12. CAMPOS, E. de S. - Sôbre a paraplegia na moléstia de Chagas obtida experimentalmente com cultura de $T$. cruzi. Demonstração das lesōes e dos parasitos na medula espinhal e outros órgãos. Bol. Soc. Med. Cir. São Paulo $7: 114-115,1925$.

13. CAMPOS, E. de S. - Sur la paralysie des animaux (chien, souris) infectés expérimentalement avec les cultures de Trypanosoma cruzi. C. R. Soc. Biol. (Paris) 93:40-42, 1927.

14. CAMPOS, E. de S. - Paralisia determinada pelo Trypanosoma cruzi de origem humana. Bol. Biol. 9:153-173, 1927.

15. CAMPOS, E. de S. - Estudos sôbre uma raça neurotrópica de Trypanosoma cruzi. An. Fac. Med. São Paulo 2:197-201, 1927.

16. CAMPOS, E. de S. - Studies upon a neurotropic strain of Trypanosoma cruzi. J. Tech. Meth. 12:146-147, 1929.

17. CHAGAS, C. - Nova tripanosomiase humana. Mem. Inst. Oswaldo Cruz 1: 159-218, 1909.

18. CHAGAS, C. - Nova entidade mórbida no homem. Resumo geral de estudos etiológicos e clínicos. Mem. Inst. Oswaldo Cruz 3:-219-275, 1911.

19. CHAGAS, C. - Les formes nerveuses d'une nouvelle trypanosomiase (7'rypanosoma cruzi) inoculé par Triatoma megista. Nouv. Iconogr. Salpêtrière $26: 1-9,1913$.

20. CHAGAS, C. - Processos patogênicos da trypanosomiase americana. Mem. Inst. Oswaldo Cruz 8:5-36, 1916.

21. CHAGAS, C. - Trypanosomiase americana: forma aguda da moléstia. Mem. Inst. Oswaldo Cruz 8:37-69, 1916.

22. CHAGAS, C. - Estado atual da trypanosomiase americana. Rev. Biol. Hig. $5: 58-64,1934$.

23. COURSEY, E. de - The first fatal case of Chagas disease observed in the isthmus of Panama. Amer. J. Trop. Med. 15:33-40, 1935.

24. CROWELL, B. C. - The acute form of American Trypanosomiasis; notes on its pathology with autopsy report and observation on trypanosomiasis cruzi in animals. Amer. J. Trop. Med. 3:425-454, 1923.

26. DIOS, R. L.; ZUCCARINI, J. A. \& OYARZABAZ, J. - Citados por Elejalde, P.28.

27. DIAS, J. C. - Citado por Elejalde, P.28. 
28. ELEJALDE, P. - Alguns achados no liquido cefalorraquidiano na forma aguda da doença de Chagas. An. Congr. Intern. Doença de Chagas 2:491$502,1961$.

29. ELEJALDE, P. - Lesões cerebrais na doença de Chagas aguda. An. II Congr. Lat. Amer. Anat. Patol. 78-79, 1958.

30. ELIZALDE, F. - Enfermedad de Chagas-Mazza; meningoencefalitis aguda en un lactante. Arch. argent. Pediat. 38:225-231, 1952.

31. FREITAS, J. L. P. - Contribuição para o estudo do diagnóstico da moléstia de Chagas por processos de laboratório. Tese de doutoramento, Faculdade de Medicina da Universidade de São Paulo, 1947.

32. FREITAS, J. L. P. - O diagnóstico de laboratório na moléstia de Chagas. Rev. Clin. São Paulo 28:1-10, 1952.

33. FREITAS, J. L. P. - Sôbre a transmissão intra-uterina da infecção pelo Trypanosoma cruzi. Rev. Hosp. Clin. Fac. Med. São Paulo 5:1-8, 1950.

34. FREITAS, J. L. P.; LION, M. F. \& TARTARI, J. T. A. - Resultados de uma investigaçāo sôbre moléstia de Chagas realizada no município de Marília e outros, com estudo clínico de dois casos agudos. Rev. Hosp. Clín. Fac. Med. São Paulo 8:81-92, 1953.

35. FREITAS, J. L. P. \& MENDES, R. T. - Investigaçōes sorológicas na forma nervosa crônica da moléstia de Chagas entre pacientes internados em hospital psiquiátrico. Rev. paul. Med. 46:123-126, 1955.

36. JARDIM, E. - Consideraçōes sôbre a transmissão materno-fetal do S'chisotripanum cruzi em camundongos. An. XII Sem. Deb. Cient. (Pôrto Alegre), 1956.

37. JARDIM, E. - Alterações quantitativas das células de Purkinje na fase aguda da moléstia de Chagas experimental do camundongo. Tese de doutoramento, Faculdade de Medicina de Ribeirão Prêto, 1962.

38. JARDIM, E. - Comunicação pessoal.

39. KÄFER, J. P.; POCH, G. F.; MONTEVERDE, D. A.; BLANCO, E. F. \& TARSIA, R. - Las manifestaciones neurológicas en la forma crónica de la enfermeđad de Chagas. Rev. Neurol, Buenos Aires 9:199, 1961.

40. KOBERLE, F. - Patogenia da moléstia de Chagas. Rev. Goiana Med. 3:155$180,1957$.

41. KöBERLE, F. - Patofisiologia da moléstia de Chagas. II Congr. Lat. Amer. Anat. Patol., 1958.

43. KOBERLE, F. - Patologia da moléstia de Chagas. Medicina (C.A.R.L., Ribeirão Prêto) 1:73-98, 1962.

44. KOFOID, C. A. \& col. - The cycle of Trypanosoma cruzi in tissue culture of embryonic heart muscle. Univ. Calif. Publ. Zool. 41:23-24, 1935.

45. LARANJA, F.; DIAS, E. \& NOBREGA, G. - Citados por Mello, A. \& Mello, N. R.52. 
46. LEVY, H. - Forma nervosa da moléstia de Chagas. Rev. paul. Med. 32: 315, 1948.

47. LOMONACO, D. A. - Estudo da funcão tireoidiana na forma crônica da moléstia de Chagas. Tese de Livre Docência, Faculdade de Medicina de Ribeirão Prêto, 1962 .

48. MACIEL, P. - Citado por Alencar, A. \& Elejalde, P..

49. MARTINEZ-COLOMBRES, B. \& BOCCA TOURRIS, D. - Citados por Elejal de, P. ${ }^{28}$.

50. MAZZA, S.; FRERE, R. S. \& SALICA, P. N. - Formas meningoencefálicas primitivas e secundarias de la enfermedad de Chagas. Considerable gravedad del proceso y tratamiento adecuado con 7602 (Ac) Bayer. Misión Estud. Pat. reg. argent. (MEPTA) 43:36-40, 1942.

51. MELARAgNo Filho, R. - Afecções Vasculares Cerebrais. Livraria LusoEspanhola-Brasileira, São Paulo, 1959.

52. MEllo, A. \& MEllo, N. R. - A forma nervosa crônica da doença de Chagas. Rev. Inst. Adolfo Lutz 15:194-222, 1955.

53. MOREIRA, J. V. C. - A forma nervosa da moléstia de Chagas. Tese de doutoramento, Faculdade de Medicina do Rio de Janeiro, 1925.

54. MUSACCHIO, M. O. \& MEYER, H. - Açāo do Esquisotripanum cruzi degenerado ou em suspensāo de tripanosomas mortos sôbre células nervosas em culturas de embriāo de galinha. An. Congr. Intern. Doença de Chagas 3: 1065-1068, 1962

55. NADOR, E. - Contribuiçāo ao estudo das lesōes no sistema nervoso central da moléstia de Chagas experimental. An. II Congr. Lat. Amer. Anat. Patol., 1958.

57. NATHAN LARRIER, L. - 1928 (citado por Freitas, J. L. P. \& col.34.

58. NUSSENZVEIG, I.; WAJCHENBERG, B. L.; MACRUZ, R.; SPINA-FRANCA, A.; TIMONER, J. \& SERRO AZUL, L. G. - Acidentes vasculares cerebrais embólicos na cardiopatia chagásica crônica. Arq. Neuro-Psiquiat. (São Paulo) 11:386-402, 1953.

59. OKUMURA, M.; CORReA NETTO, A. \& SIlVA, A. C. - Contribuição para o estudo da patogenia das lesōes vasculares na doença de Chagas experimental em camundongos brancos. Rev. paul. Med. 61:265-266, 1962.

60. REIS, L. C. F. - Estudo sôbre anormalidades observadas em curvas glicêmicas na moléstia de Chagas. Tese de doutoramento, Faculdade de Medicina de Ribeirão Prêto, 1963.

61. REZENDE, C. L. - Doença de Chagas e acidentes cerebrais agudos. Rev. brasil, Med. 10:354-355, 1953.

62. REYES, O. H. \& SUTTIN, O. B. - Enfermedad de Chagas con chagomas múltiplos y paralisia facial bilateral. I Reun. Panamer. Enf. Chagas 1:83-89, 1950. 
63. RIU, J. A. \& GENIS, H. P. - Sobre un caso de claudicación circulatória cerebral en una enfermedad de Chagas. Rev. Neurol. Buenos Aires 19:204-205, 1961.

64. ROBERT, M. R. G. - South American trypanosomiasis of meningo-encephalomyelitic type in New York. J.A.M.A. 92:230-231, 1929.

65. ROMAÑA, C. - Encefalopatias de posible origen esquisotripanósico. An. Inst. Med. Reg. 2:19-39, 1947.

66. ROMAÑA, C. \& MEYER, H. - Citados por Köberle, F."2,

67. RONCHI, O. J. \& ARA, C. A. - Meningoencefalitis chagásica en un lactante de cuarenta y cinco dias. Arch. argent. Pediat. 39:268-274, 1953.

68. TORRES, C. M. - Sôbre a anatomia patológica da doença de Chagas. Mem. Inst. Oswaldo Cruz 36:391-394, 1941.

69. SCHWARTZBURD, H. \& KöBERLE, F. - Chagas Myelopathie. Z. Tropenmed. Parasit. 10:309-314, 1959.

70. TORRES, C. M. \& VILLAÇA, J. - Encefalite e mielite causadas por um trypanosoma (T. cruzi). Mem. Inst. Oswaldo Cruz 19:72-79, 1919.

71. TORRICO, R. A. \& TORRES, J. R. - Caso agudo de enfermedad de Chagas con chagoma de inoculación, diatesis hemorrágica, esquisotripánide morbiliforme y syndrome meningoencefálico. An. Labor. Central 3:32-36, 1951.

72. VIANNA, G. - Contribuiçāo para o estudo da anatomia patológíca da moléstia de Carlos Chagas (Esquizotripanose humana ou tireoidite parasitária). Mem. Inst. Oswaldo Cruz 3:276-394, 1911.

73. VICHI, F. L. - Estudo do parasitismo na medula espinal de ratos na fase aguda da moléstia de Chagas. Rev. Inst. Med. Trop. São Paulo 3:37-42, 1961.

74. VICHI, F. L. - Moléstia de Chagas experimental (parasitismo na cadeia ganglionar simpática, medula espinhal, gânglio raquidiano e musculatura estriada). Hospital (Rio de Janeiro) 64:131-139, 1963.

75. VILlELA, E. - Moléstia de Chagas: forma nervosa. Fôlha Med. (Rio de Janeiro) 4:49-52, 1923.

76. VILlELA, E. - A transmissão intra-uterina da moléstia de Chagas. Encephalite congênita pelo Trypanosoma cruzi (nota prévia). Fôlha Med. (Rio de Janeiro) 4:41-43, 1923.

77. VILLELA, E. - Paralysie expérimentale chez le chien par le Trypanosoma cruzi. C. R. Soc. Biol. (Paris) 91:979-983, 1924.

78. VILlELA, E. - Variação do poder pathogenico do Trypanosoma cruzi (raça neurotrópica). Cienc. Med. 3:2-3, 1925.

79. VILlELA, E. \& TORRES, C. M. - Lésions histopathologiques dans la paralysie expérimentale à Schizotrypanum cruzi chez le chien: nature des cellules contenant le parasite dans le système nerveux central. C. R. Soc. Biol. (Paris) 93:133-134, 1925. 
80. Villela, E. \& TORRES, C. M. - Estudo histopatológico do sistema nervoso central em paralisia experimental determinada pelo Schizotrypanum cruzi. Mem. Inst. Oswaldo Cruz 19:175-198, 1926.

81. Villela, E. \& Villela, E. - Elementos do sistema nervoso central parasitados pelo Trypanosoma cruzi. Mem. Inst. Oswaldo Cruz 26:77-79, 1932.

82. Villela, E. \& BiCAlHo, C. - As pesquisas de laboratório no diagnóstico da moléstia de Chagas. Mem. Inst. Oswaldo Cruz 16:13-29, 1923.

83. WOLF, A. \& COWEN, D. - Chagas' äisease. J. Neuropath. Exp. Neurol. 18: 209-210, 1959.

84. ZACLIS, J.; CRUZ, O. R. \& ALMEIDA, G. G. M. - Obstrucões das artérias carótidas e das principais artérias cerebrais. Arq. Neuro-Psiquiat. (São Paulo) 14:158-170, 1956.

Departamento de Cirurgia, Faculdade de Medicina - Caixa Postal $301-$ Ribeirũo Prêto, SP - Brasil. 